\title{
Use of electric vehicles or hydrogen in the Danish transport sector
}

\author{
Skytte, Klaus; Pizarro Alonso, Amalia Rosa; Karlsson, Kenneth Bernard
}

Published in:

Proceedings of the International Conference on Energy, Environment and Climate Change (ICEECC 2015)

Publication date:

2015

Document Version

Publisher's PDF, also known as Version of record

Link back to DTU Orbit

Citation (APA):

Skytte, K., Pizarro Alonso, A. R., \& Karlsson, K. B. (2015). Use of electric vehicles or hydrogen in the Danish transport sector. In Proceedings of the International Conference on Energy, Environment and Climate Change (ICEECC 2015) (pp. 197-214)

\section{General rights}

Copyright and moral rights for the publications made accessible in the public portal are retained by the authors and/or other copyright owners and it is a condition of accessing publications that users recognise and abide by the legal requirements associated with these rights.

- Users may download and print one copy of any publication from the public portal for the purpose of private study or research.

- You may not further distribute the material or use it for any profit-making activity or commercial gain

- You may freely distribute the URL identifying the publication in the public portal

If you believe that this document breaches copyright please contact us providing details, and we will remove access to the work immediately and investigate your claim 


\title{
ICEECC \\ International Conference on Energy, Environment and Climate Change \\ Use of electric vehicles or hydrogen in the Danish transport sector in order to ensure a stable and sustainable energy system in 2050 ?
}

\author{
Klaus Skytte*, Amalia R. Pizarro and Kenneth B. Karlsson
}

Systems Analysis Division, Department of Management Engineering, Technical University of Denmark, Risø Campus, DK-4000 Roskilde, Denmark

*Corresponding Author. E-mail: Klsk@dtu.dk, Tel: +45 93511085

\begin{abstract}
:
Denmark is one of the Northern European countries that have set up ambitious longterm targets to reduce GHG emissions from the transport as well as from other sectors. In Denmark the target is to make the transport sector independent of fossilfuel consumption by 2050 at the latest. This paper compares a likely scenario with two alternative ways to achieve the goal - either with a high percentage of electric vehicles $(E V)$ or with a high percentage of hydrogen $\left(\mathrm{H}_{2}\right)$ use in the transport sector.

The STREAM model - an energy scenario simulating tool - provides insight into different potential energy mixes and calculates socio economic costs. It is used to model the different transport scenarios and their system integration with the electricity and heating sectors.

The major findings of this paper are that an increased share of electric vehicles could significantly reduce the socio-economic cost of the energy system in 2050. Electricity demand for $\mathrm{H}_{2}$ generation via electrolysis is more flexible than EV charging and the production can therefore, to a larger degree be used to out-balance variable electricity surplus from a high share of wind and solar energy in the power system.
\end{abstract}

$\mathrm{H}_{2}$ production may generate heat that can be used as district heating - replacing traditional heating plants, heat pumps and in some cases combined heat and power plants. Therefore the energy generation mix (electricity and heat) is more affected in the $\mathrm{H}_{2}$ scenario than in the EV scenario.

Whether the $\mathrm{H}_{2}$ scenario is more costly to implement than the EV scenario mainly depends on the technological development - especially the improvement on the efficiency of the conversion from electricity to $\mathrm{H}_{2}$. It is found that a higher efficiency in the $\mathrm{H}_{2}$ production via electrolysis plays a more important role in decreasing the total cost of the energy system than a lower level of electrolyser capital cost. Therefore, the major driver of a successful $\mathrm{H}_{2}$ scenario is a high efficient and flexible $\mathrm{H}_{2}$ production in 2050. In other words, from a socio-economic view point this paper 


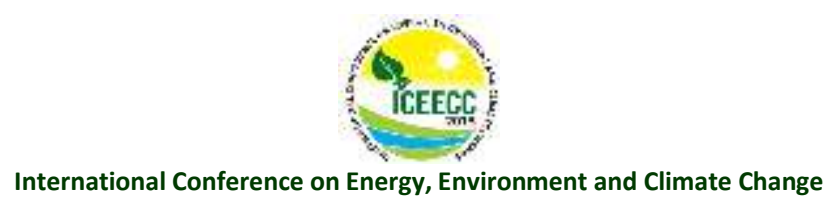

estimates that the technological path in innovation should have efficiency as its main driver towards 2050.

Keywords: Energy, Environment, Electric vehicles (EV); hydrogen use; renewable energy; e-mobility; STREAM model

\section{Introduction}

Use of fuels based on renewable energy sources (RES) are getting favoured by the Northern European countries in the transport sector. The main reason for this is that use of RES based fuels in transportation will help decrease the environmental impacts of this sector. In addition, it will increase the diversification of the fuel supply, and thereby reduce reliance on traditional fossil fuel sources for transport.

At present in Denmark, the transport sector accounts for approximately $50 \%$ of the total costs of the energy system and around 30\% of the greenhouse gas (GHG) emissions [1]. Furthermore, nowadays the transport sector is practically independent from the power and heat generation; however, in the future their interrelations will be stronger. The Danish electricity supply sector is converting from fossil towards RES based electricity generation with a high share of wind energy. Wind power provided a world record of $41.2 \%$ of Danish electricity consumption for the first 6 months of 2014. In 2020, it is assumed that $50 \%$ of the yearly electricity generation will come from wind energy [2]; and in 2035, the political goal is to have 100\% RES based electricity generation in Denmark, which includes a high share of wind energy.

An increased share of variable and un-dispatchable electricity production from wind and photovoltaic in the system will require as much flexibility in electricity demand as possible. Therefore, in the coming years there will be a transformation of the different sectors of the energy system, through long-term integration of renewable energy without jeopardizing security of supply.

With electricity based on RES, the use of electric vehicles (EV) or hydrogen-fuelled vehicles, where hydrogen $\left(\mathrm{H}_{2}\right)$ has been produced via electrolysis, does not emit GHG emissions. However, an increase of electricity demand for transportation imposes a requirement of a very flexible demand side in the transportation sector and the rest of the energy system. Charging of EV and production of $\mathrm{H}_{2}$ via electrolysis offer to some extent very flexible demand and production patterns.

It is important to make a holistic analysis of the transport and energy sectors since many of the RES can be used in all sectors, e.g. biomass can be used to provide electricity, heat or biofuels. In addition, an increased production of $\mathrm{H}_{2}$ to the transport sector or an increased use of EV imply an increase in the electricity demand and thereby affect the electricity system and the district heating (affecting production from cogeneration plants or via heat from $\mathrm{H}_{2}$ production). These are the reasons why an integrating modelling tool is required in order to evaluate plausible future scenarios. 


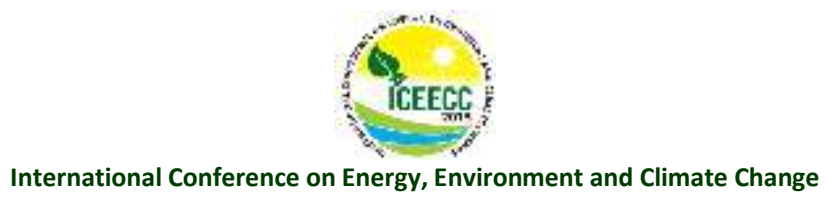

Also the limitation of resources may affect the future energy sectors. Since biomass is a relative limited resource in Denmark, the use of domestic biomass will most probably be used where no other alternatives exists, in order to obtain a fossil-free energy system in 2050 [3]. A fossil-free transport sector based on biomass based fuels would absorb very large amounts of bioenergy in 2050. The two major alternatives to biomass based RE-fuels in the transport sector is electricity and hydrogen. Therefore, it is obvious to look for alternative scenarios with focus at either EV or $\mathrm{H}_{2}$. These scenarios also reflect situations where there is additional focus on sustainability and alternative uses of biomass outside the energy sector, or where the risk of high biomass prices is large.

In order for $\mathrm{EV}$ or $\mathrm{H}_{2}$ vehicles to become key technologies, it will require a significant financial incentive in the form of e.g. tax exemptions, particularly in the first part of the period and that the price for EV and $\mathrm{H}_{2}$ technologies decreases. In addition, we can assume that battery technology is still being developed and made cheaper, so EV get significantly better range and more applications.

It is assumed that electric vehicles can be competitive with other car types, which is supported by the IEA Energy Technology Perspectives 2012 [4], which states "If batteries follow the cost path of many other technologies, electric vehicles may reach cost competitiveness if enough are manufactured in the coming decade".

Today more than $99 \%$ of all vehicles at the Danish roads use either gasoline or diesel (Figure 1).

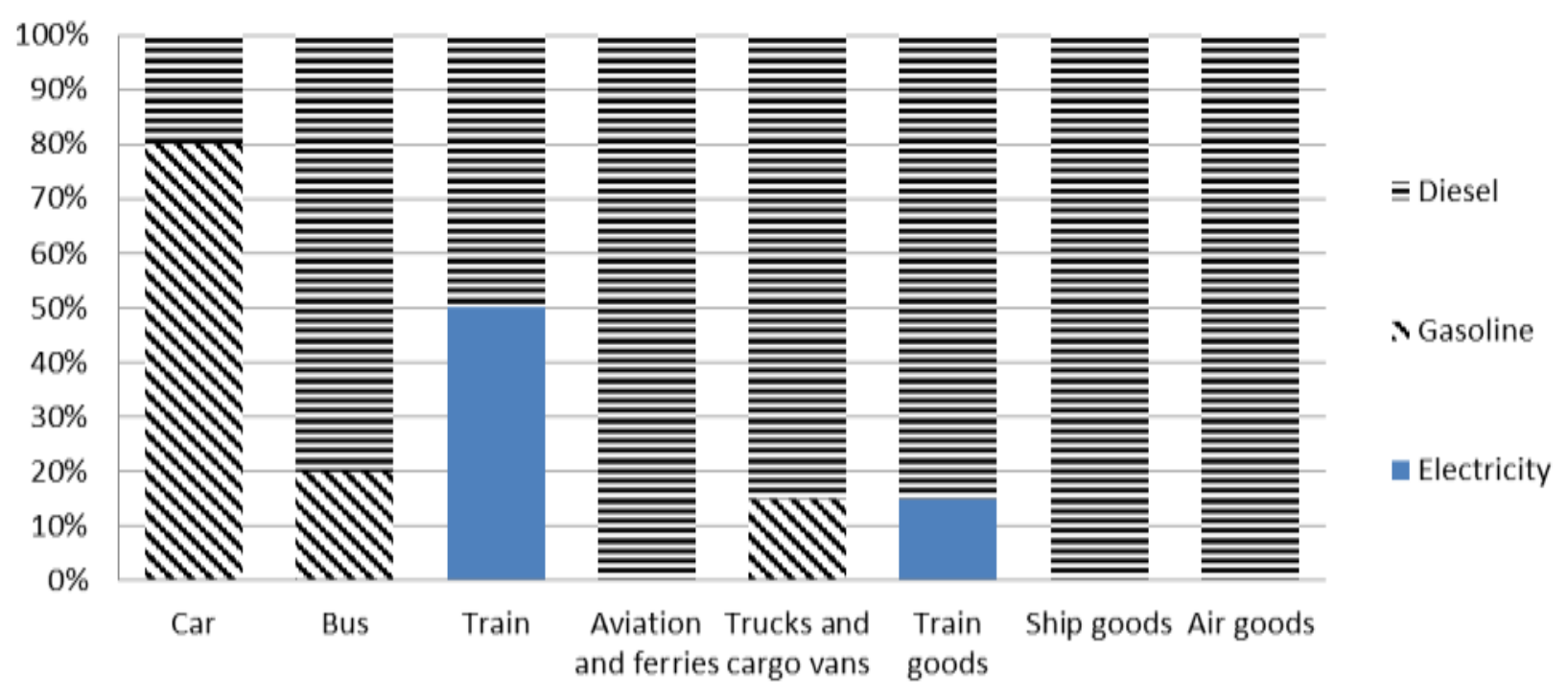

Figure 1: Fuel use today in Denmark (2012). Measured as fuel consumption in percent person

transportation work $(\mathrm{p} \mathrm{km})$ or percent freight transportation work $(\mathrm{t} \mathbf{\mathrm { km }})$ 


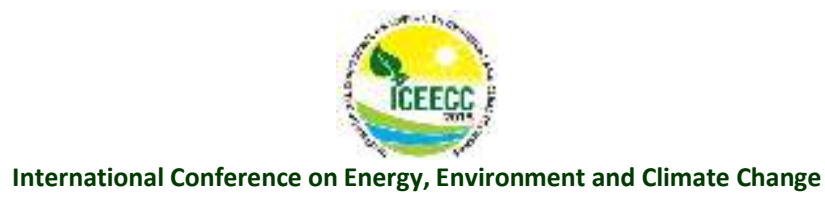

Therefore, a radical restructuring of the fuel use and vehicle stock has to be made in order to reach a fossil-free transport sector in 2050. Such a large radical restructuring will require substantial political indorsement, the right framework and infrastructure as well as technological development in the non-fossil technologies.

Without analyses it is not clear at which costs and how well the political decisions and the choice of technologies and fuel use in the transport sector will interact with the energy sector - especially a 100\% RES based electricity sector. This paper compares a likely scenario for the Danish transport sector in 2050 with two alternative ways to achieve the 2050-goal - either with a high percentage of EV or with a high percentage of $\mathrm{H}_{2}$ use in the transport sector.

By use of the simulation model STREAM we are able to analyse the transport scenarios and their system integration with the electricity and heating sectors by 2050 .

Without analyses it is not obvious which technological path the innovation of EV and $\mathrm{H}_{2}$ technologies shall take. Is it most important to decrease the capital cost? Or is most important to create flexible technologies? Or to increase the efficiencies and thereby reducing the fuel consumption? The model studies in this paper look at it from a socio-economic view point and with sensitivity analyses we are able to estimate which parameters maters the most.

There are several papers about use of $\mathrm{EV}$ or $\mathrm{H}_{2}$ and their possible benefits for the flexibility in the electricity system. Juul and Meibom [5],[6] use the optimization model, Balmorel, to analyse an optimal configuration and operation of the integrated power and road transport systems in Northern EU. Their focus is at the choice of fuel mix on the power market. They find that it is optimal to use coal for charging EV in Finland and Germany. Whereas it is optimal to use hydro and wind in the other Nordic countries. Kiviluoma and Meibom [7] estimates the costs of plug-in electric vehicles (EVs) in a future power system by use of a technical optimization model for the Nordic electricity markets. They find that the benefits of flexible charging of the $\mathrm{EV}$ is $227 € /$ vehicle/year.

Kristoffersen et al [8] finds that EV provides flexibility almost exclusively through charging. Moreover, the EV provide flexibility within the day but only limited flexibility from day to day when driving patterns are fixed. Rösler et al [9] compares $\mathrm{EV}$ and $\mathrm{H} 2$ with respect to oil prices. They find that if battery costs are reduced by at least $60 \%$ in comparison to their reference cost decline path, the passenger car sector could predominantly run on electricity from around 2050. van der Zwaana et al [10] investigate possible evolution pathways for the transport sector. Hennings et al [11] show how excess generation from wind turbines in Germany can be used to charge EV.

Most of the exiting studies look at present or near future energy systems. This paper expand the above mentioned studies by looking at 2050 for the Nordic countries 


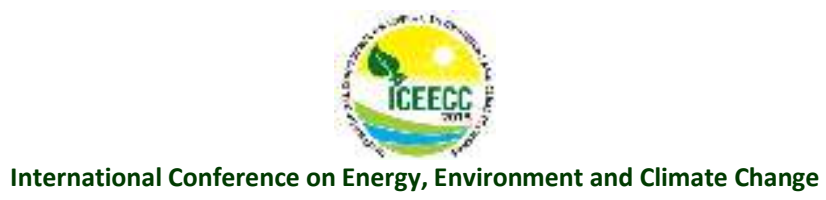

where there is a very high share of variable wind energy and where the transport and energy sectors have become fossil free.

\subsection{The STREAM model}

The different transport scenarios are developed in the model STREAM (Sustainable Technology Research and Energy Analysis Model), which is a public-domain open source model (http://www.streammodel.org). STREAM is a scenario building tool that provides an overview of the complete energy system on both the demand and supply side.

STREAM is capable of delivering fast, user-friendly pictures of both present and future energy situations. The model allows planners, politicians, students and others to be able to create scenarios.

The model depicts the complete energy flow; from fuel exploration, conversion and energy use, across all sectors in the society, including the transport sector. Whereas, many other models only focus on certain parts of the energy system, for example the dispatching of power plants in the electricity sector and the district heating system; STREAM allows simulating different scenarios and comparing their solutions for the system, considering the electricity, heat and transport system at the same time [12][13].

The modelling tool consists of two spreadsheet sub-models, as illustrated inFigure 2: the energy flow model and the duration curve model. Both are based on a bottom-up approach. This means that the user defines the input to the models - for instance, $X$ percent wind power in the electricity sector or X percent bioethanol in the transport sector - and on this basis an output is calculated. Hence, the model does not perform an economic optimisation, specifying exactly which set of measures are the most advantageous to combine under given conditions. However, operation of the energy system with the given conditions is optimized, to assure that the energy demand is satisfied at every time while minimizing the installed capacity of energy plants, and therefore, investments. 
INDUTS

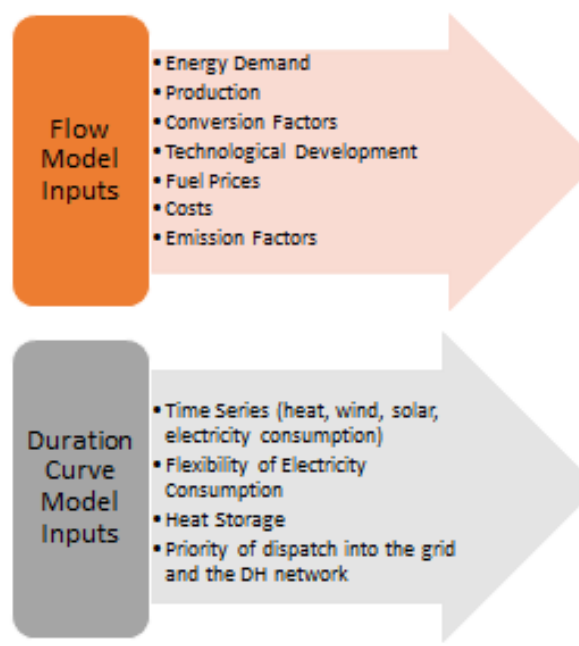

MODEL CALCULATIOAS

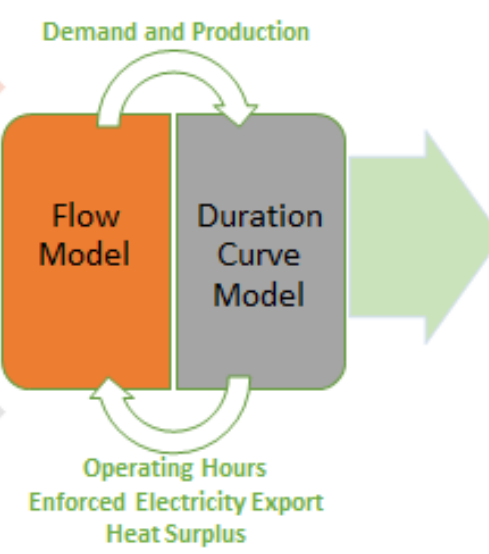

OUTDUTS

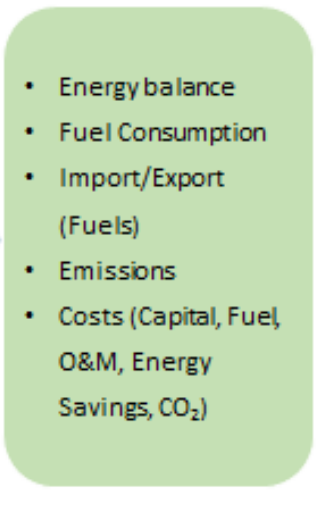

Figure 2. Linkage between Flow Model and Duration Curve Model in STREAM [14]

The model works and interacts in the following way [14]:

- The Energy Flow Model: demand \& supply. It is a static model assessing and arranging the total energy system in a given year. The demand for energy services is projected and consequently the final energy consumption is calculated, according to the defined inputs for supply. It creates an overview of GHG emissions, energy resources and fuel conversion. The Flow Model can be run independently of the Duration Curve Model in a stand-alone mode for simplified analyses using estimates of full load hours, condense based production of cogeneration plants and electricity overflow.

- The Duration Curve Model: system balancing. It analyses correlations in the electricity and district heating systems on an hourly basis: uncontrollable vs. dispatchable electricity, combined heat and power, district heating generation, storage devices, flexible and inflexible demand, etc. Based on the analyses of the Duration Curve Model, input is provided to the Flow Model, modifying the initial overall energy flow and economical calculations, estimated through assumptions during the stand-alone simulation (without synchronization with the Duration Curve Model).

In STREAM, transportation is modelled as four independent sectors: passenger, freight, agriculture and fishery. The current transport work; person $\mathrm{km}$, ton $\mathrm{km}$ and energy consumption in agriculture and fishery; is stated. The demand in the year of simulation is forecasted by setting values for expected economic growth and specific intensity factors (i.e. how much transportation work increases when each sector growths). Once the demand is calculated, transportation sectors are described, so as to enable their simulation within the energy system. The user defines the allocation of 


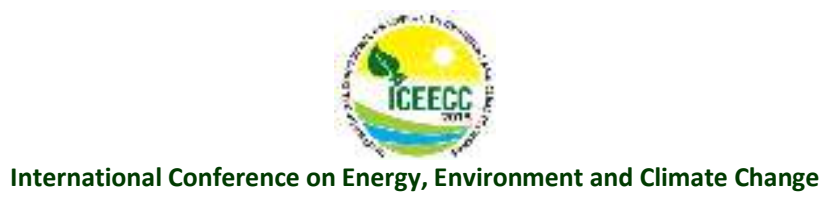

transport work by vehicle type (e.g. car, bus, train, plane, bike, etc.), the utilization degree (or stocking density) and the composition of fuels for transportation means for passenger and freight transport and agriculture and fishery. Associated costs and emissions related to fuel production and consumption and vehicle acquisition and maintenance are accounted. Flexible fuel production and charging of vehicles is modelled through the Duration Curve spreadsheet.

All datasets used by STREAM are from publicly available sources. Data used in the model in this paper are Danish technology specific data [1][15][16]. Cost for expanding power transmission lines to the surrounding countries and the possibility that the capacity of the lines will be restricted is not taken into account in the modelling of the Danish energy system.

Previous studies that have been completed using STREAM include a study on demand projection and cost-efficient potential of GHG and oil consumption reductions in the Baltic Sea region (including all or part of ten countries in total) [17]; as well as developing scenarios for GHG emissions reduction that can provide a basis for estimating which technologies should be combined in order to do it in an economical way [18]; and examining how the EU goals on improved security of supply and reductions in GHG emissions can be fulfilled efficiently in Denmark [19].

\section{Description of the 2050 Scenarios}

This paper compares three scenarios for the Danish transport sector in 2050 - a likely scenario with two alternative ways to achieve the 2050-goal - either with a high percentage of $\mathrm{EV}$ or with a high percentage of $\mathrm{H}_{2}$ use in the transport sector.

The overall framework in the energy as well as in the transport sectors for the likely scenario for 2050 is a Danish development similar to the carbon neutral scenario (CNS) in Nordic Energy Technology Perspectives [4]. With respect to transport, this, as well as the two other scenarios in this paper, is based on the CNS projection of demand for passenger and freight transport by 2050. These projections are made based on historical trends for transport work and economic growth as well as assumptions for future demand, transport work, efficiency improvements and technology switch.

In our CNS scenario the fuel mix in the transport sector is similar to the CNS scenario in the Nordic Energy Technology Perspective. For the two other scenarios in this paper, we change the fuel mix towards respectively electricity and hydrogen.

In 2050 the fuel mix in the CNS scenario (Figure 3) is very diverse compared to the present fuel mix (Figure 1). 95\% of all trains are electrified. Almost $40 \%$ of all passenger transport in cars is done in EV. Ethanol and biodiesel are widely used with biodiesel as the main substitute for traditional diesel compared to the present fuel mix. 


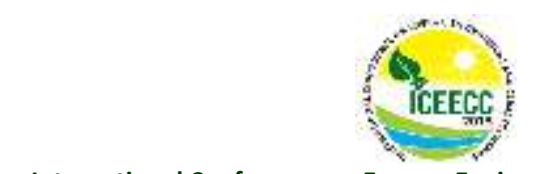

International Conference on Energy, Environment and Climate Change

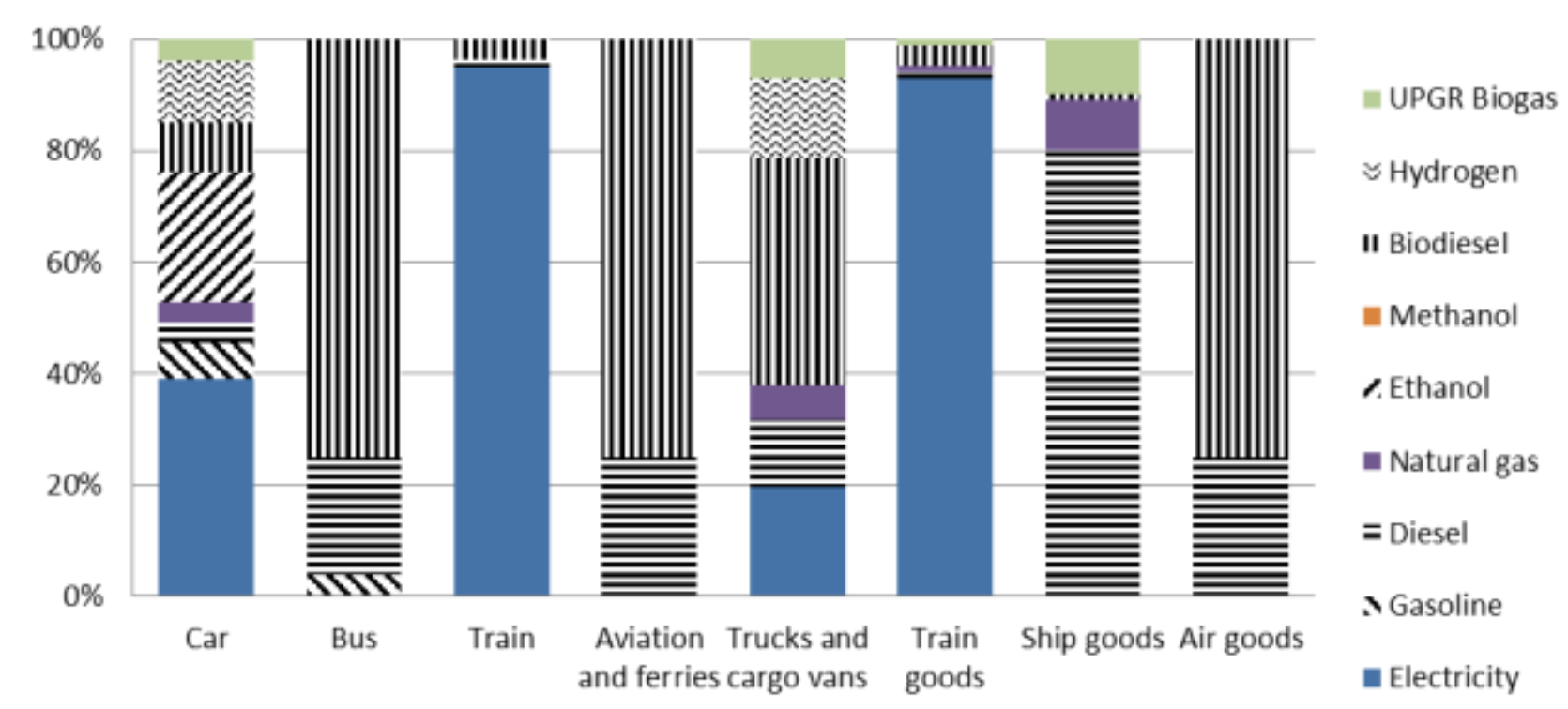

Figure 3: Fuel use in transport sector in the Carbon Neutral Scenario (CNS) 2050.

Measured as fuel consumption

in percent person transportation work $(\mathrm{pkm})$ or percent freight transportation work (tkm)

In the electricity sector, wind energy will be the major supplier of electricity in 2050 (Table 1). Coal and natural gas is phased out in order to reach a fossil-free electricity production.

In 2050, it is assumed that domestic electricity production is equal to domestic demand on a yearly basis, i.e. yearly import equals export. However, daily and hourly uses of the transmission lines are allowed in the model in order to flatten out excess or deficit generation.

Table 1: Technology mix in the electricity and heating sectors in the CNS scenario compared to the present mix.

\begin{tabular}{lcc|lcc|} 
Eletricity production & & & \multicolumn{3}{l}{ District Heat boiler production } \\
\hline & $\mathbf{2 0 1 2}$ & CNS 2050 & & $\mathbf{2 0 1 2}$ & CNS 2050 \\
Coal Plant & $57 \%$ & $0 \%$ & Coal boiler & $1 \%$ & $0 \%$ \\
Gasturbine & $23 \%$ & $0 \%$ & Natural gas boiler & $47 \%$ & $0 \%$ \\
Wind, offshore & $4.3 \%$ & $56 \%$ & Geothermal & $2 \%$ & $0 \%$ \\
Wind, onshore & $18 \%$ & $27 \%$ & Heatpump & $0 \%$ & $21 \%$ \\
Biomass & $9 \%$ & $4 \%$ & Wood pellet boiler & $31 \%$ & $76 \%$ \\
Biogas & $1 \%$ & $4 \%$ & Oil boiler & $15 \%$ & $0 \%$ \\
Waste incineration & $7 \%$ & $5 \%$ & Biogas Boiler & $1 \%$ & $1 \%$ \\
Photo voltaic & $0 \%$ & $2 \%$ & Municipal waste & $3 \%$ & $3 \%$ \\
Wave power & $0 \%$ & $1 \%$ & Electric boiler & $1 \%$ & $0 \%$ \\
Biomass incl. CO2-storage & $0 \%$ & $2 \%$ & Solar heat & $1 \%$ & $0 \%$ \\
\hline Demand coverage & $118 \%$ & $100 \%$ & Demand coverage & $100 \%$ & $100 \%$ \\
Electricity imports & $-18 \%$ & $0 \%$ & Heat import & $0 \%$ & $0 \%$
\end{tabular}




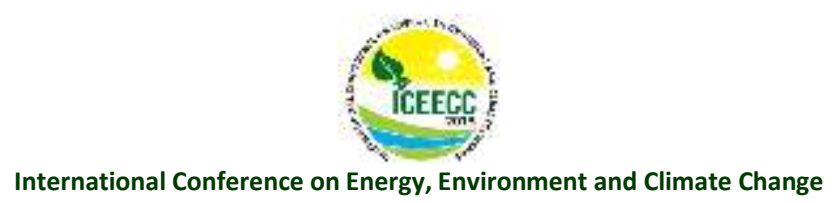

In the two alternative scenarios $\left(\mathrm{EV}\right.$ and $\left.\mathrm{H}_{2}\right)$ the use of imported biomass is assumed to be limited. In addition, use of electricity or $\mathrm{H}_{2}$ instead of biofuels in the transport sector imply less heat from biofuel refinery and thereby, a need for further boilers to district heating. This is reflected in the district heating sector where as much municipal waste as possible (compared to the domestic resources) is used in order to minimise import of biomass. Wood pellet based boilers for heat goes from $76 \%$ of the heat production in the CNS scenario to $28 \%$ in $\mathrm{EV}$ and $\mathrm{H}_{2}$ scenarios, and municipal waste boilers goes from $3 \%$ in the CNS to $51 \%$ in the EV scenario, i.e. $48 \%$ from wood pellet to municipal waste.

In the EV scenario, electric vehicles (EVs) have become a cornerstone technology in the transport system which therefore focuses to a greater degree on EV as a measure to obtain fuel and $\mathrm{CO}_{2}$ savings in the transport sector. The EV scenario performs a massive electrification of the transport sectors to keep bioenergy consumption down.

In 2050 the transport sector has become fossil-free and the fuel mix in the EV scenario (Figure4) is much more homogeneous compared to the CNS scenario (Figure ). Electricity and biodiesel are the main fuels. Hydrogen is not used in the transport sector.

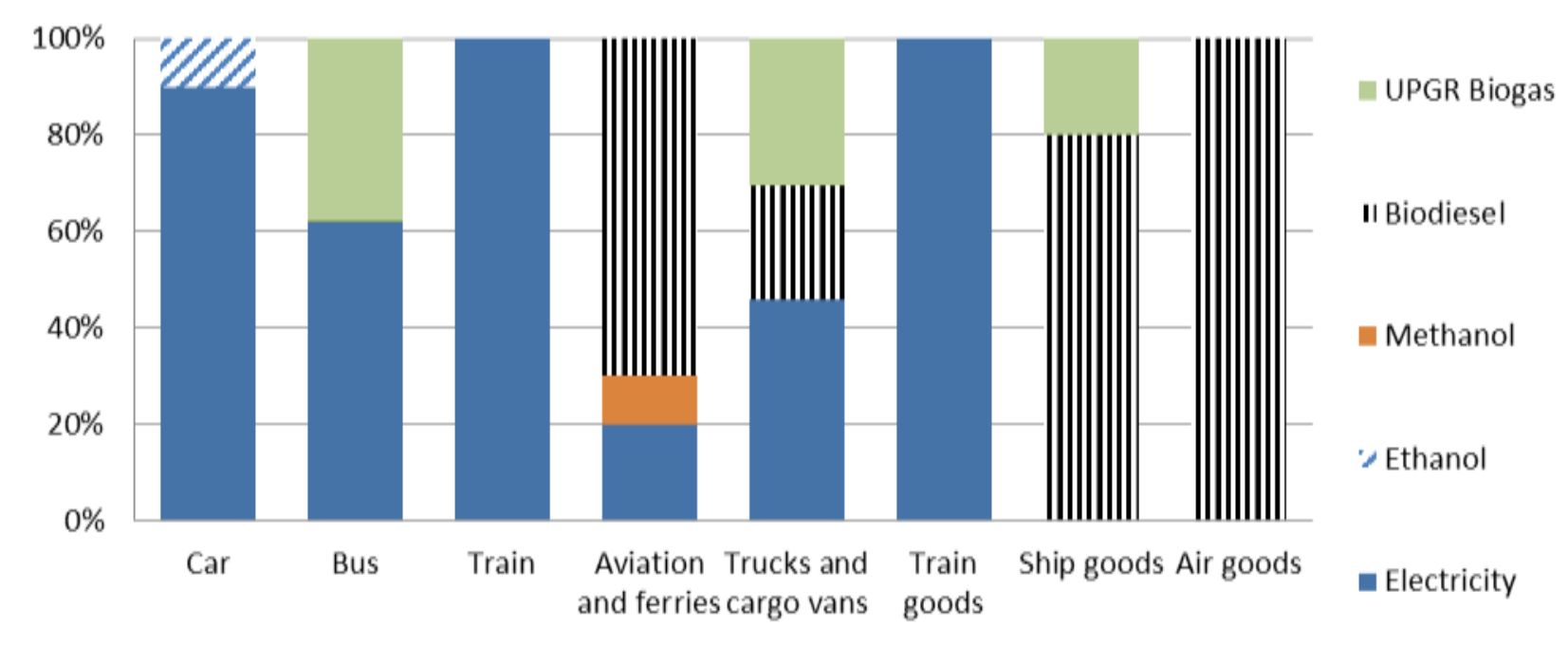

Figure 4: Fuel use in the EV scenario 2050. Measured as fuel consumption in percent

person transportation work $(\mathrm{p} \mathrm{km})$ or percent freight transportation work $(\mathrm{t} \mathrm{km})$

In the $\mathrm{H}_{2}$ scenario hydrogen is the highway to a fossil free transport sector. This scenario assumes an early commercial breakthrough for use of hydrogen in the transport sector. 


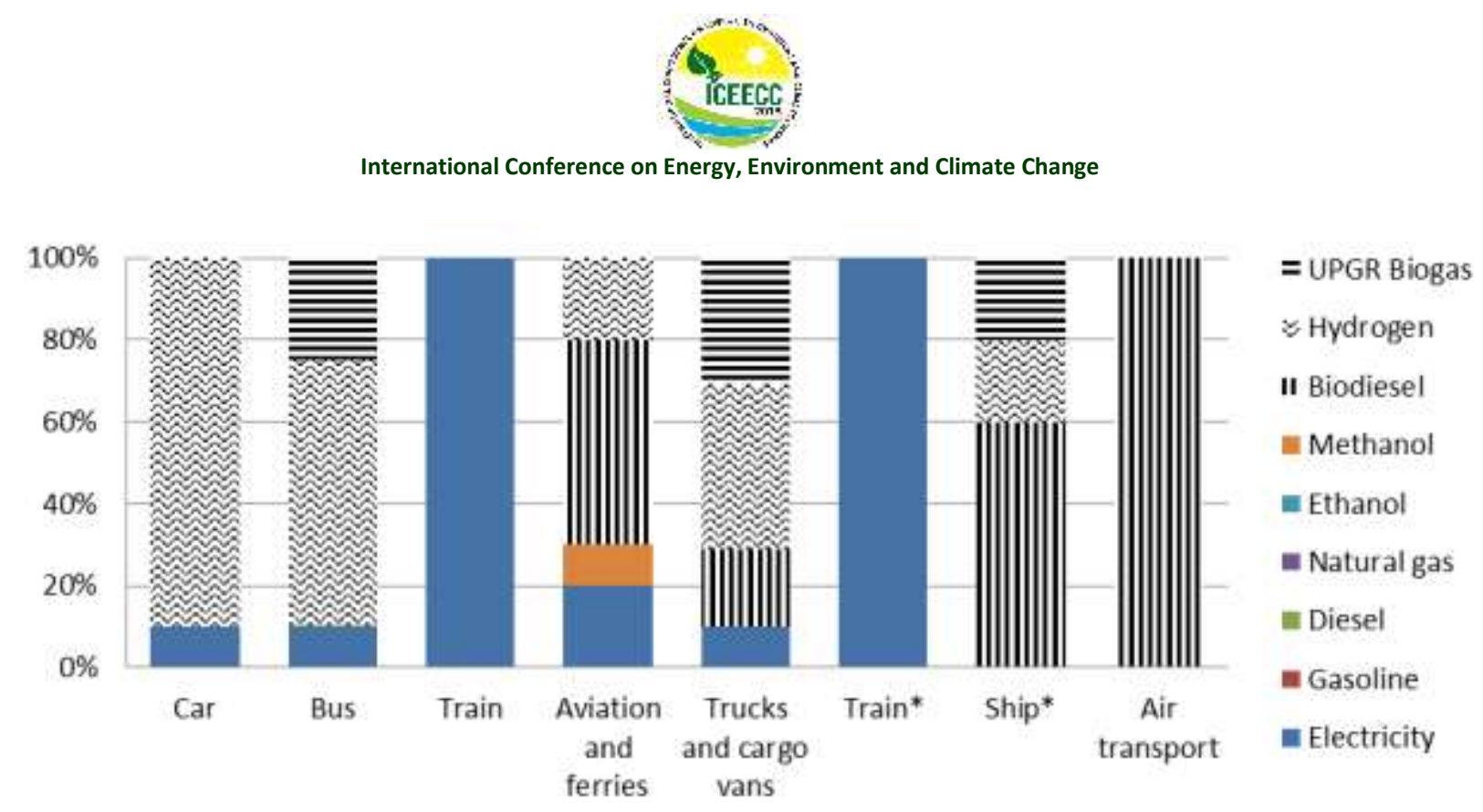

Figure 5: Fuel use in the $\mathrm{H}_{2}$ scenario in 2050. Measured as fuel consumption in percent person transportation work $(\mathrm{p} \mathrm{km})$ or percent freight transportation work $(\mathrm{t} \mathbf{\mathrm { km }})$

$\mathrm{H}_{2}$ has become the main fuel for passenger transport in $2050-90 \%$ of all cars and $65 \%$ of all buses are using $\mathrm{H}_{2}$. The $\mathrm{H}_{2}$ scenario involves in addition to a large share of wind energy a significant hydrogen production in the energy sector. It is assumed that $\mathrm{H}_{2}$ generation is made via electrolysis which implies an additional demand for electricity for $\mathrm{H}_{2}$ production.

\section{Scenario results}

\subsection{CNS to EV}

The EV scenario implies a $14 \%$ increase in total electricity demand compared to the CNS scenario in 2050 , with $27 \%$ of the total electricity demand from the transport sector.

There is a need for more boilers to district heating since the EV scenario keeps biofuels consumption down in the transport sector and thereby, supersedes district heating from bio-refinery compared to the CNS scenario. The heat production from boilers is increased from 9 to 15 PJ due to less heat production from bio-refinery. However, use of municipal waste can take a large share of the new boilers (accordant to the resources in DK).

The larger electricity demand and the wish to keep import of biomass low imply a larger share of wind energy in the electricity supply. In 2050 wind generates $82 \%$ of the total electricity generation per year in Denmark. This implies relative large fluctuations in the power production from hour to hour compared to the demand (Figure 66). The green pattern in Figure 66 presents wind generation. Together with $\mathrm{PV}$ this power generation is the most fluctuating production. 


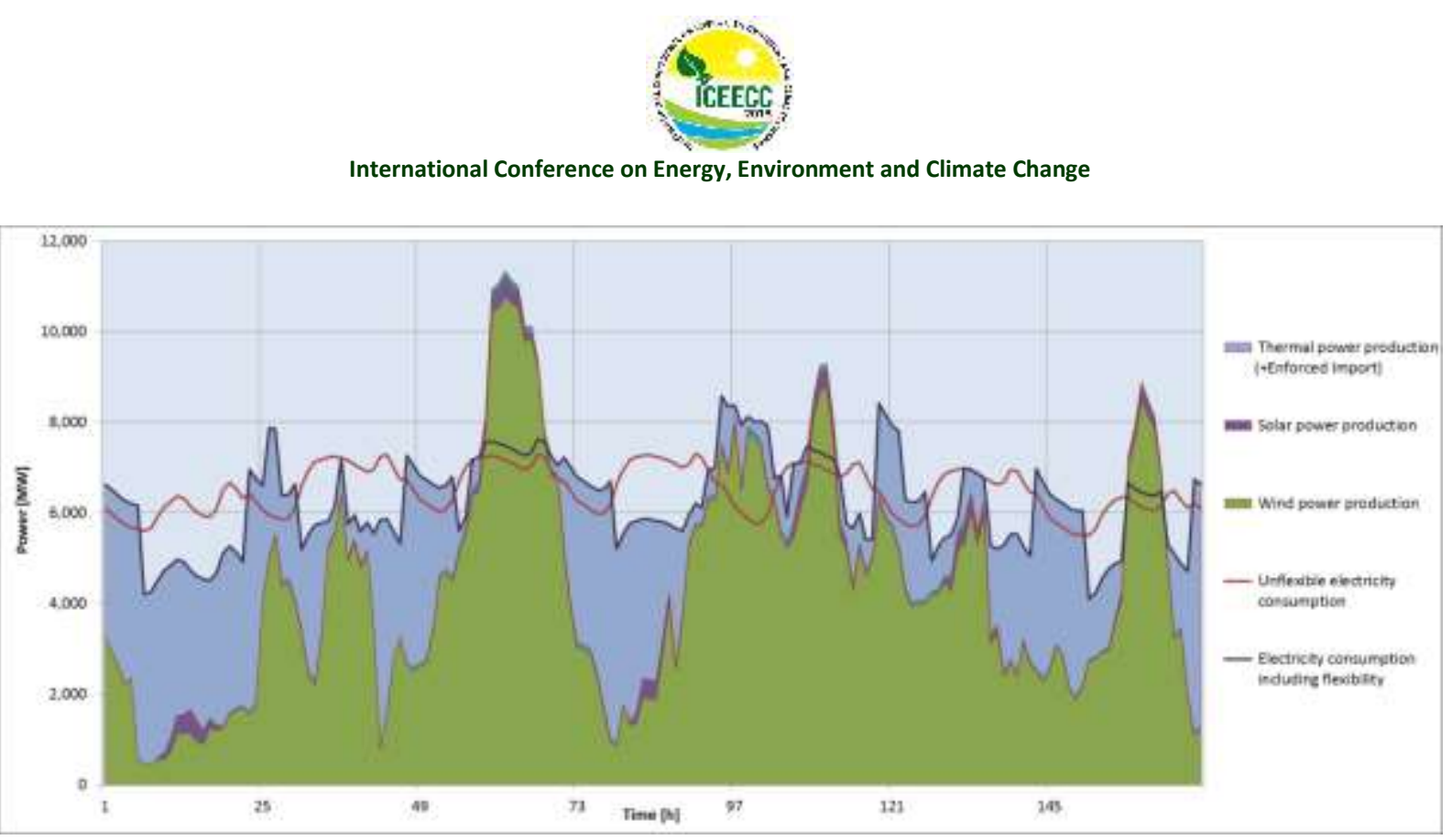

Figure 6: Power generation and consumption with and without flexible demand in week 10 in year 2050. Model simulations.

The more flexible the consumption the easier it is for the system to cope with a large share of fluctuating production and thereby keep cost for backup capacity down. In other words, the more flexible the charging of the EV is the easier it is to operate a power supply system with such a high share of wind energy. Figure 6 shows two cases. In the flexible consumption case, $40 \%$ of all EVs are assumed to be flexible in charging their batteries during the week - all other assumptions been kept constant. And additional $40 \%$ flexibility during night time (23h $-6 \mathrm{~h})$ each day, i.e. during night $80 \%$ of EV can deliver a flexible electricity demand for charging the EVs.

It is seen that when there is a surplus of wind the model increase the demand in the flexible case. And vice versa in hours with less wind production than electricity demand, the model decreases the consumption.

In order to keep cost for backup capacity down the model uses the flexible demand to minimise the thermal capacity (the difference between the demand and the fluctuating RES-E production - the blue area for each hour in Figure 6). In hours with a large difference the demand is decreased as much as possible.

Since the charging of EV is more flexible during night hours we see larger demand peaks during these hours, where consumption has been shifted from daytime to night time.

Looking at the entire energy system, we find that the overall cost is lower in the EV scenario than in the CNS scenario (see Figure 7). 

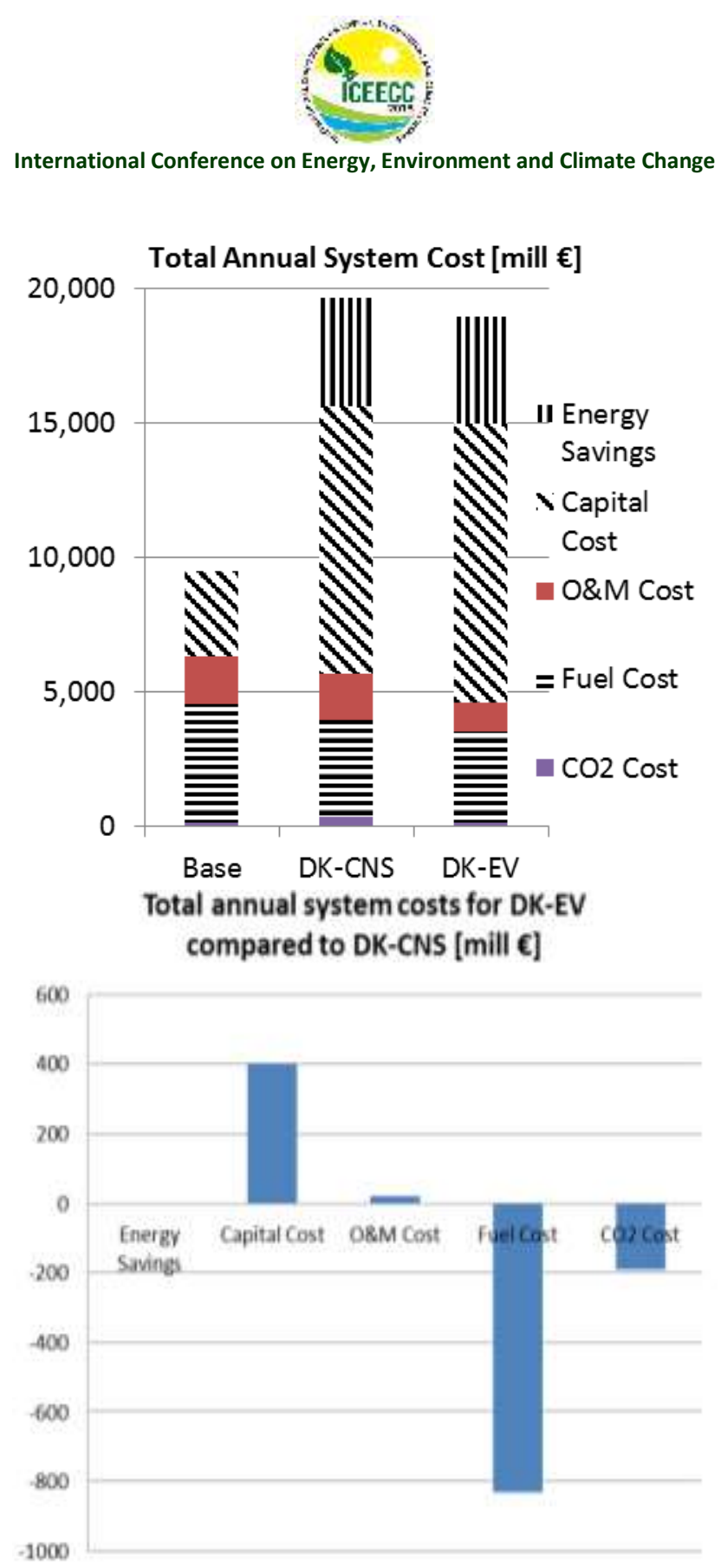

Figure 7: Total annual system costs in 2050 and the difference between the CNS and the EV scenario (mill $€$ ).

These numbers can be segmented sector-wise in order to find the main driver of this. When looking at the cost of the EV scenario a doubling of capital cost in the transport sector is found. It is assumed that EVs are around $40 \%$ more costly than traditional gasoline vehicles when charging stations and rental of batteries are included in the capital costs. In the electricity sector all costs increase (fuel and capital cost). However the savings in the transport and refinery sectors are larger, which implies that in total there is a saving of 607 million $€$ in the EV scenario compared to the CNS scenario. This corresponds to a $3.1 \%$ decrease. This is mainly due to the large saving on fuel cost in the system. 


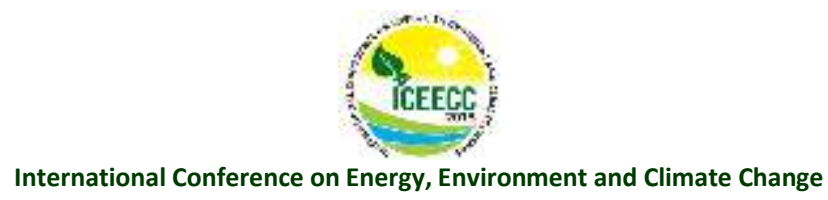

More capital cost is needed in the electricity sector due to a larger demand for electricity. However, less capital cost is needed in refineries. So in total for these two sectors the capital cost is lower in the EV scenario than in the CNS scenario. Therefore, the main driver of the total increase in capital cost is from the cost of EV. The increase in the transport sector is around 5\% (267 mio $€)$.

As seen in Figure saved fuel costs is the main reason why the EV scenario is less expensive to implement than the CNS scenario. The model finds slightly higher fuel cost for electricity due to more electricity generation. However, the fuels used for electricity are cheaper than the fuels used for bio-fuels in the transport sector (e.g. waste compared to energy crops for bio-fuels). In total this implies a large saving in fuel costs.

\section{$3.2 \mathrm{H}_{2}$ scenario results}

The electricity demand is increased by $63 \%$ in the $\mathrm{H}_{2}$ compared with the CNS scenario. The reason is that we have assumed that all $\mathrm{H}_{2}$ is produced by electrolysis. Compared to the EV scenario this is a major increase in the power demand.

$\mathrm{H}_{2}$ production via electrolysis is flexible and the production can therefore be used to out-balance fluctuating electricity generation from a high share of wind energy in the energy system (Figure 8).

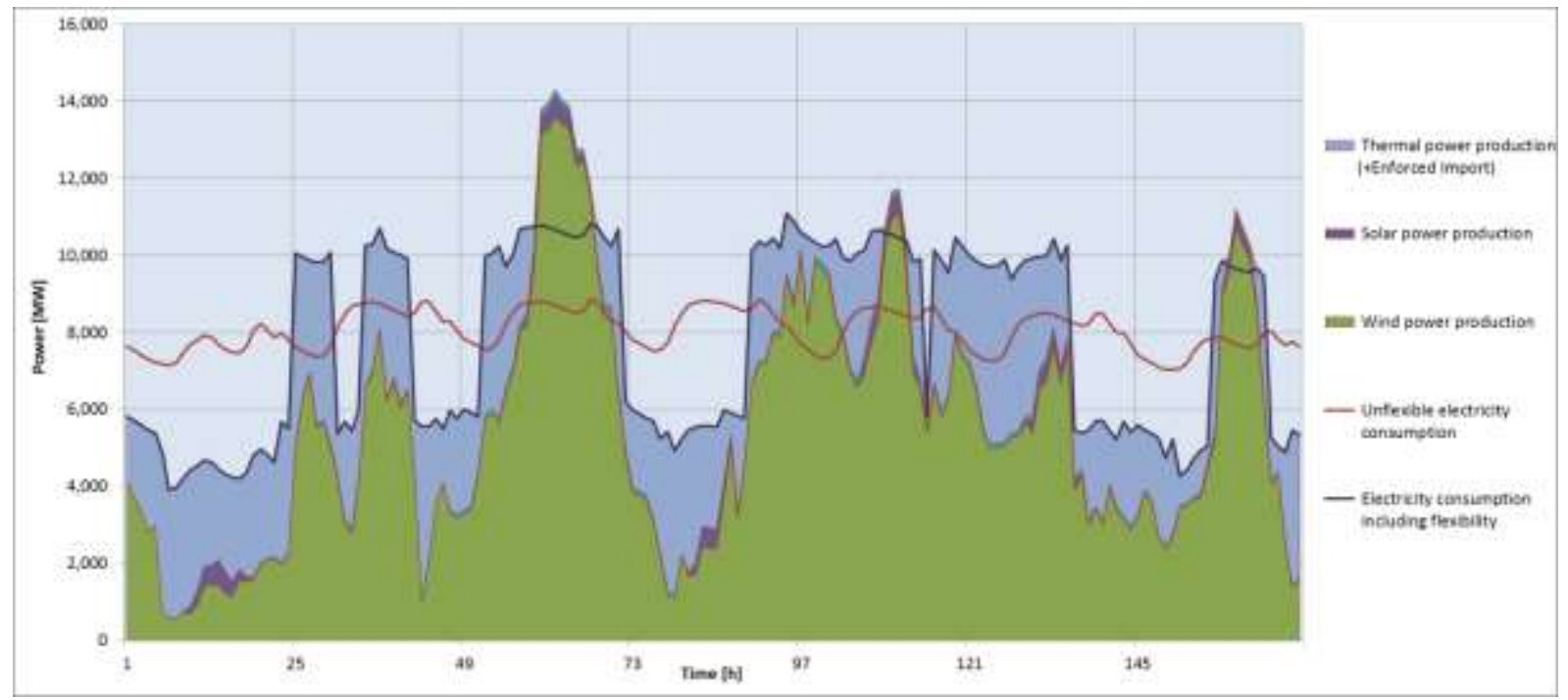

Figure 8: Power generation and consumption with and without flexible demand in week 10 in year 2050 in $\mathrm{H}_{2}$ scenario.

Compared to the EV scenario it is seen that power demand in the $\mathrm{H}_{2}$ scenario is much more flexible than in the EV scenario (Figure 6 compared to Figure ).

$\mathrm{H}_{2}$ production via Alkaline electrolysis generates heat that can be used as district heating - replacing traditional heating plants, heat pumps and in some cases 


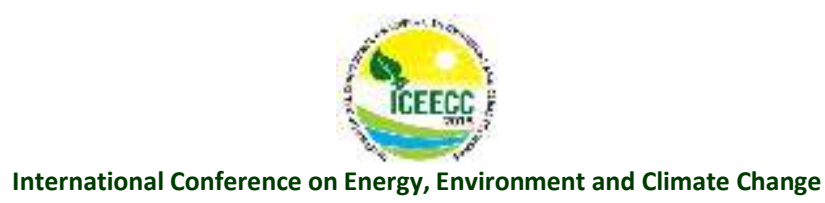

combined heat and power plans. Therefore the electricity generation mix is more affected in the $\mathrm{H}_{2}$ scenario than in the EV scenario.

The $\mathrm{H}_{2}$ scenario is more costly to implement than the EV or CNS scenarios (Figure 9). The reason is a much higher total capital costs in the system $(14 \%$ higher than the CNS scenario). Due to the large amount of required new electricity the capital cost is very large. Compared to the CNS scenario, the additional capital costs are more than three times larger for the $\mathrm{H}_{2}$ scenario than for the EV scenario (the right figure in Figure compared to Figure 9).
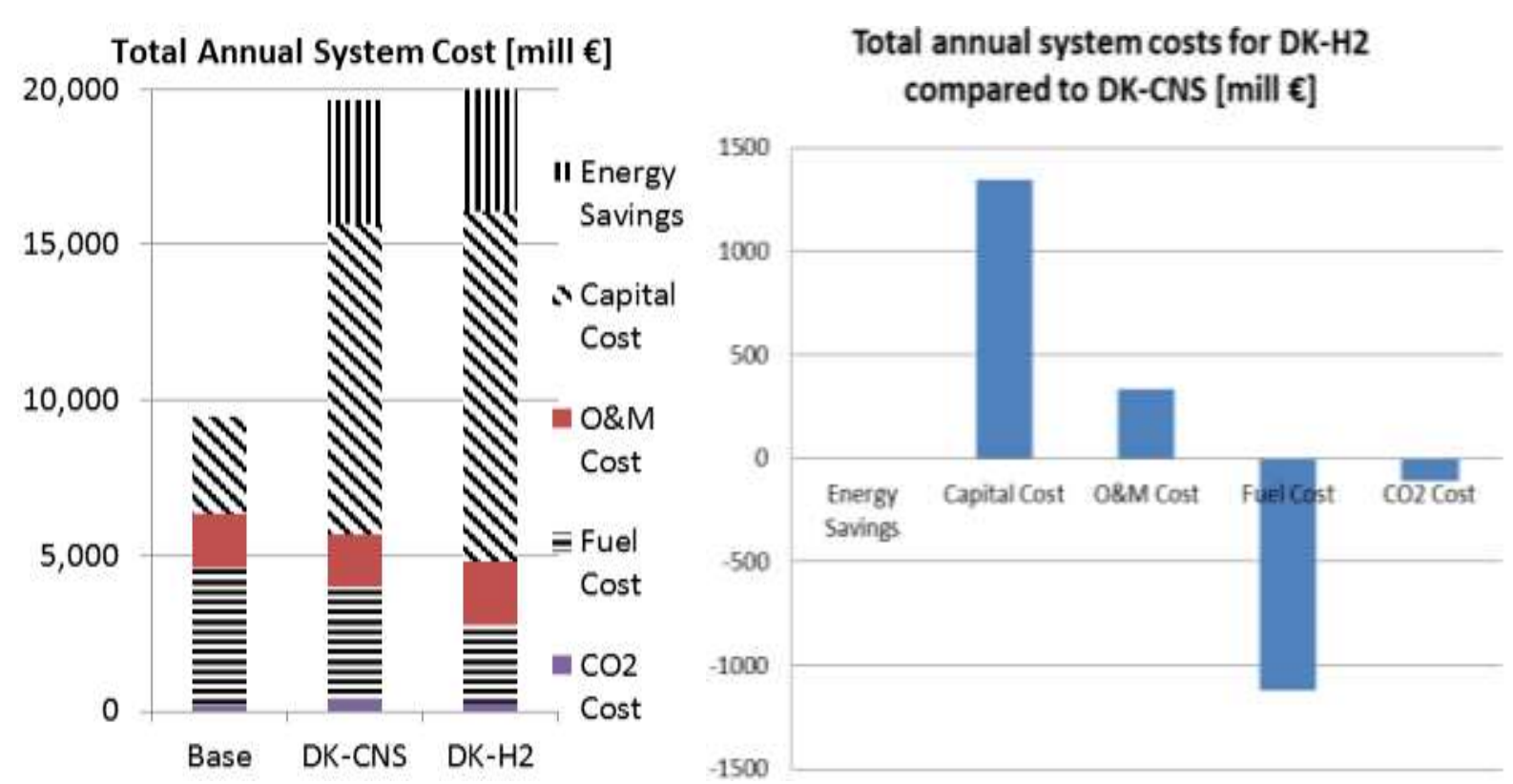

Figure 9: Total annual system costs in 2050 and the difference between the $\mathrm{H}_{2}$ and the CNS scenario (mill $€$ ).

Saved fuel costs are $35 \%$ larger in the $\mathrm{H}_{2}$ scenario than in the EV scenario compared to the CNS scenario. The saved fuel costs even, to some extent, out the additional capital costs of the $\mathrm{H}_{2}$ scenario. In total, the total socio-economic cost of the $\mathrm{H}_{2}$ scenario is $2.3 \%$ more expensive in 2050 than the CNS scenario.

\section{Which technological path should the innovation follow? Sensitivity analysis of cost drivers}

Without analyses it is not obvious which technological path towards 2050 the innovation of $\mathrm{EV}$ and $\mathrm{H}_{2}$ technologies shall take. Is it most important to decrease the capital cost? Or is it most important to create flexible technologies? Or to increase the efficiencies and thereby reduce the fuel consumption? The model studies in this paper look at it from a socio-economic view point and with sensitivity analyses we are able to estimate which cost drivers maters the most. 


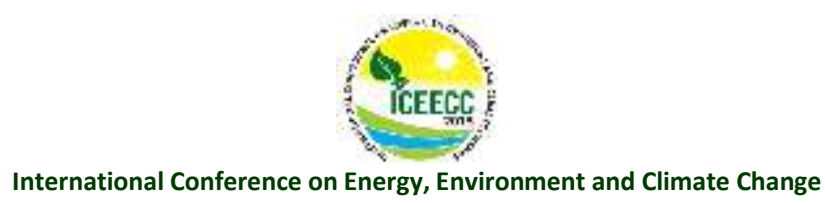

Sensitivity analyses with respect to flexible technologies where made in Figure 7 and Figure 8 where it was found that $\mathrm{H}_{2}$ production could add more flexibility to the system than EV charging. So what remains to be analysed is how much cost and efficiency improvements affect the socio-economic cost of the system. This is especially important for the $\mathrm{H}_{2}$ scenarios as it was estimated to be more expensive than the CNS scenario and since the $\mathrm{H}_{2}$ technology is less mature than the EV technology. Therefore the estimates for future cost and efficiency of $\mathrm{H} 2$ are more uncertain than for EV.

As shown in Figure 9 the $\mathrm{H}_{2}$ scenario is around 2.3\% more expensive to implement in 2050 than the CNS scenario when looking at the total annual system cost. By reducing the investment costs $^{3}$ for electrolysers in both scenarios we find out how sensible the scenario results are for technological development with respect to reduction in costs. This is illustrated by the red line in Error! Reference source not found.0.

Hydrogen is used in both the CNS and the $\mathrm{H}_{2}$ scenarios. However, since the amount of $\mathrm{H}_{2}$ is larger in the $\mathrm{H}_{2}$ scenario, the effect of the cost improvement is largest in the $\mathrm{H}_{2}$ scenarios compared to the CNS scenario. I.e. the total cost difference between the two scenarios is decreased with improvements in capital cost for $\mathrm{H}_{2}$ electrolysers.

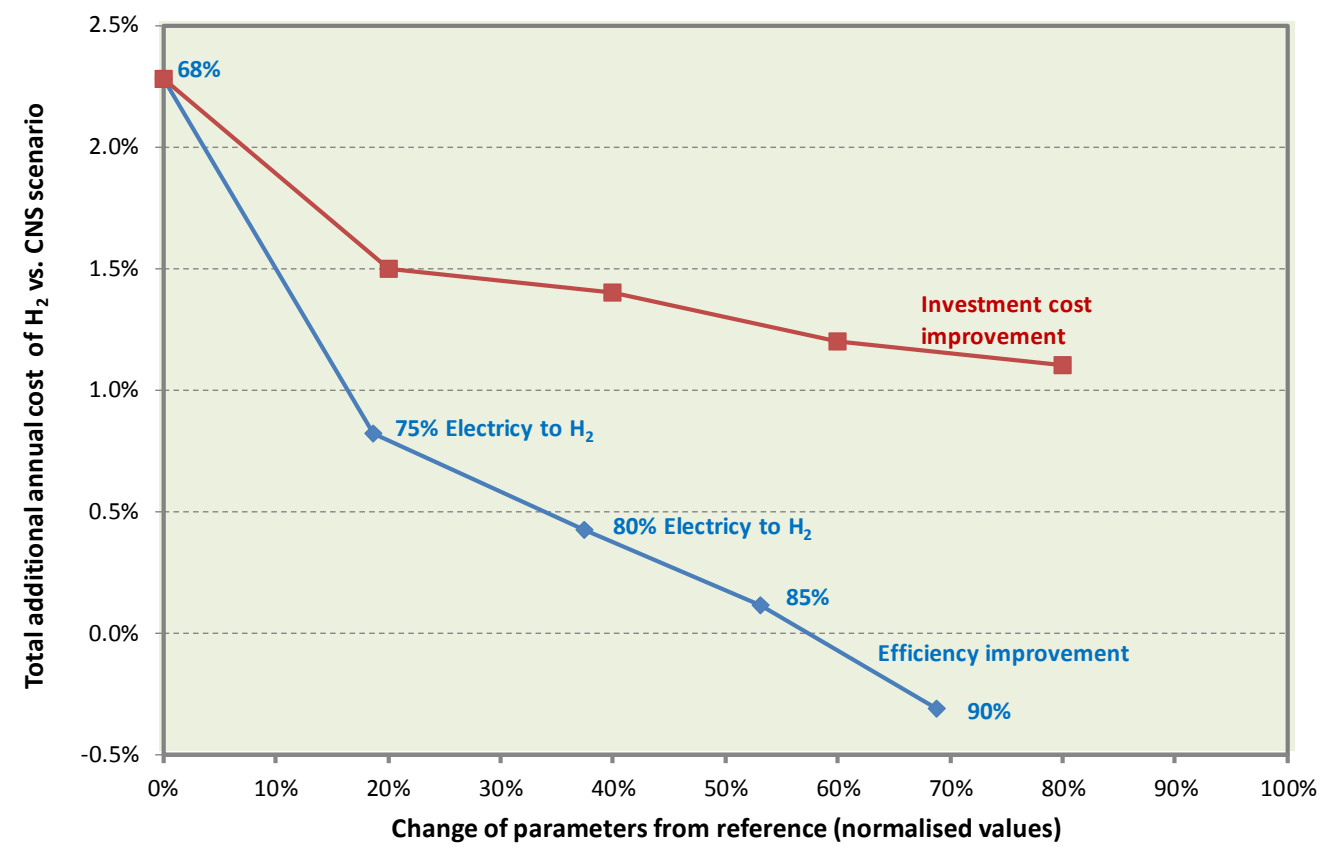

Figure 10 . Impact of technology improvement of Electrolysers in the Total System Annual Cost (Efficiency reference $=68 \%$ from electricity to $\mathrm{H}_{2}$ )

3 The reference investment cost in $\mathrm{H}_{2}$ electrolysers used in the different scenarios for 2050 is 55.7 $€ / \mathrm{GJ} /$ year. 


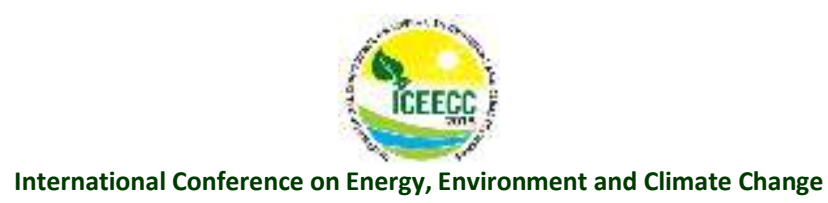

The horizontal axis indicates the improvement in the capital cost for $\mathrm{H}_{2}$ electrolysers compared to the red line. At $0 \%$ the cost is as in the reference cases as described above. A $20 \%$ decrease in costs of $\mathrm{H}_{2}$ electrolysers yield a decrease to $1.5 \%$ additional total cost for the $\mathrm{H}_{2}$ scenario compared to the CNS scenario, etc.

It is seen that the $\mathrm{H}_{2}$ scenario remains more expensive than the CNS scenario even with a very large reduction in the costs of $\mathrm{H}_{2}$ electrolysers. This is mainly due to the fact that the $\mathrm{H}_{2}$ scenario requires a large capital cost to new electricity capacity in order to cope with the increased electricity demand for $\mathrm{H}_{2}$ production compared to the CNS scenario. In other words, a decrease in the capital costs for $\mathrm{H}_{2}$ electrolysers is not by itself enough to make the $\mathrm{H}_{2}$ scenario less expensive than the CNS scenario.

The blue line in Error! Reference source not found. shows the effect of better efficiency in the $\mathrm{H}_{2}$ production from electricity to $\mathrm{H}_{2}$. The horizontal axis shows the normalised improvements in efficiency. ${ }^{4}$ It is seen that efficiency improvements have a larger effect on the cost difference between the $\mathrm{H}_{2}$ and $\mathrm{CNS}$ scenarios than the costs improvement does. It can even become cheaper to implement the $\mathrm{H}_{2}$ scenario than the CNS scenario if the efficiency is high enough. This is mainly due to the fact that an improvement in efficiency reduces the power demand for $\mathrm{H}_{2}$ production and thereby reduces the costs connected with this power production and capacity.

The findings indicate that whether the $\mathrm{H}_{2}$ scenario is more costly to implement than the EV scenario mainly depends on the technological development - especially the efficiency of the electricity to $\mathrm{H}_{2}$ development. It is found that a higher efficiency in the $\mathrm{H}_{2}$ production is more important than a lower level of the capital cost for the $\mathrm{H}_{2}$ production. Therefore, the major driver of a successful $\mathrm{H}_{2}$ scenario is a high efficient and flexible $\mathrm{H}_{2}$ production in 2050. In other words, from a socio-economic view point the finding in this paper estimates that the technological path in innovation should have efficiency as its main driver towards 2050.

Of course, if there are innovation resources enough, the optimal path would be to have a multiple approach with focus at both cost and efficiency improvements in order to benefit from both cost reductions and to make use of $\mathrm{H}_{2}$ vehicles as competitive as possible.

\section{Final remarks}

The EV scenario yield to a lower cost than the reference CNS scenario, in spite of higher investment costs in vehicles. There are some uncertainties also about how the price of the vehicle might be by 2050, therefore it could even be more profitable if EV becomes cost competitive (IEA ETP 2012).

With respect to biofuels, energy crops price are the main driver of the cost savings. Depending on how the prices for biomass evolve in a future, results might lead to

\footnotetext{
${ }^{4}$ In the reference case an efficiency of $68 \%$ is assumed in 2050 from electricity to $\mathrm{H}_{2}$, i.e. additional $32 \%$ improvement is theoretically possible. This is used to normalise the improvement following the horizontal axis in the figure. The real efficiencies are shown as labels next to the blue line.
} 


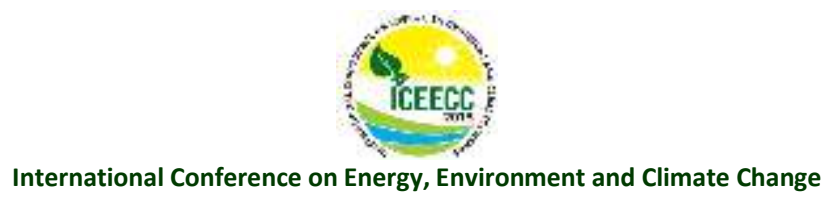

different optimal solutions [3][20]. If worldwide demand for energy crops is very high, price will be high, and Denmark, might benefit from using a higher share of EV, rather than relying on biofuels, at least, for light transport.

Both scenarios, $\mathrm{EV}$ and $\mathrm{H}_{2}$, protect the Danish transport system from dependency on fuel prices. Denmark, as a small country, will be a price-taker on the international biomass market. Therefore, fuel price increase might burden the Danish economy. Higher implementation of Electric Vehicles and Hydrogen allows having self-control of the cost of energy supply. Promoting innovation to develop cheaper EV and $\mathrm{H}_{2}$ vehicles; as well, as more efficient, flexible and less expensive electrolysers, will help to build a competitive energy system, less vulnerable to fluctuating market prices.

\section{Acknowledgement}

This paper and the model runs used in this article were developed within the TOPNEST project which is funded by Nordic Energy Research for which we are grateful. It is only the authors of this article who are responsible for the results and discussions made herein.

\section{References}

[1] Energistyrelsen; Energinet.dk, Technology Data for Energy Plants - Individual Heating Plants and Energy Transport. The Danish Energy Agency, Copenhagen, May 2012.

[2] Energistyrelsen, Energiaftalen 22. marts 2012. 2012

[3] Skytte K; Meibom P; Henriksen TC, Electricity from biomass in European Union With or without biomass import. Biomass \& Bioenergy, Vol 30, pp. 385-392, 2006.

[4] IEA and Nordic Energy Research, Nordic Energy Technology Perspectives, 2013.

[5] Juul, N., \& Meibom, P. Road transport and power system scenarios for Northern Europe in 2030. Applied Energy 92: 573-582, 2012.

[6] Juul, N., \& Meibom, P. Optimal configuration of an integrated power and transport system. Energy 36: 3523-3530, 2011.

[7] Kiviluoma, J., \& Meibom, P., Methodology for modelling plug-in electric vehicles in the power system and cost estimates for a system with either smart or dumb electric vehicles. Enegy 36, 1758-1767, 2011.

[8] Kristoffersen, TK, Capion, K., \& Meibom, P., Optimal charging of electric drive vehicles in a market environment, Applided Energy 88, 1940-1948, 2011.

[9] Rösler, H., van der Zwaan, B., Keppo, I., \& Bruggink, J, Electricity versus hydrogen for passenger cars under stringent climate change control. Sustainable Energy Technologies and Assessments 5: 106-118, 2014

[10] van der Zwaan, B.; Keppo, I., \& Johnsson, F, How to decarbonize the transport sector?. Energy policy 61: 562-573, 2013.

[11] Hennings, W., Mischinger, S., \& Linssen, J, Utilization of excess wind power in electric vehicles. Energy policy 62: 139-144, 2013.

[12] Connolly; Lund; Mathiesen; Leahy, A review of computer tools for analysing the integration of renewable energy into various energy systems. Applied Energy, Vol 87 pp. 1059-1082, 2010. 


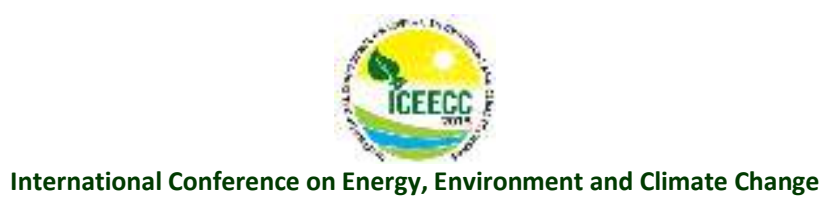

[13] Skytte, K \& Skjerk Christensen, P., BRUS2. An energy system simulator for long term planning. Revista Mexicana de Fisica, vol 45, no. 5, pp. 532-538, 1999.

[14] Münster M; Larsen H; Iversen J, STREAM Manual. August 2014.

[15] Energistyrelsen, Alternative drivmidler i transportsektoren 2.1, The Danish Energy Agency, Copenhagen, May 2013.

[16] Energistyrelsen, Energiscenarier frem mod 2020, 2035 og 2050. The Danish Energy Agency, Copenhagen March 2014.

[17] Ea, Energy Perspectives of the Baltic Sea Region interim report: study on the enhance regional energy cooperation. Report, Copenhagen, 2009.

[18] Ea; Risø, Danish Greenhouse Gas Reduction Scenarios for 2020 and 2050. Ea Energy Analyses, Risø National Laboratory; 2008.

[19] Kofoed-Wiuff A, Werling J, Markussen P, Behrmann M, Pedersen J, Karlsson K, The future Danish energy system: technology scenarios. The Danish Board of Technology; 2007.

[20] Thomsen, AB, Thomsen, MH, Maarschalkerweerd, CV, Skytte, K, Olsen, HS, Christensen, BH \& Zacchi, G, 'Energy supply technologies. Bioethanol for transport', Risø energy report 6. Future options for energy technologies. Risø National Laboratory, pp. 49-53. Denmark. 2007. 